\title{
Informação e inclusão social: perspectivas possíveis
}

\author{
Information and social inclusion: possible perspectives
}

\author{
Felipe Gabriel Gomes Medeiros \\ Doutorando em Ciência da Informação \\ Universidade Federal de Pernambuco \\ felipemedeiroz@gmail.com \\ Nadi Helena Presser \\ Doutora em Engenharia de Produção \\ Universidade Federal de Pernambuco \\ nadihelena@uol.com.br
}

\begin{abstract}
Resumo
Discute a relação entre os conceitos de informação e inclusão social a partir de referencial teórico interdisciplinar. Para tanto, estabelece a ideia de dimensão informacional da exclusão social, compreendida como o conjunto de aspectos relacionados ao fenômeno informacional no complexo e multidimensional processo de exclusão, acirrado pelo estabelecimento de uma nova ordem sociotécnica mundial, centrada no conhecimento, na informação e nas tecnologias. Conclui apontando trajetórias possíveis para atuaçã̃o de cientistas e profissionais da informação na promoção da inclusão social, com foco no acesso a recursos de informação e no desenvolvimento de competências informacionais.
\end{abstract}

\section{Palavras-chave}

Informação. Inclusão Social. Profissionais da Informação.

\section{Abstract}

The present study discusses the relationship between the concepts of information and social inclusion from an interdisciplinary theoretical framework. To this objective, it establishes the idea of informative dimension of social exclusion, comprising as a set of aspects related to the informational phenomenon in the complex and multidimensional process of exclusion, accentuated by the establishment of a new world socio-technical order, centered on knowledge, information and technologies. Concludes pointing the possible paths for scientists and information professionals to promote social inclusion, focusing on access to information resources and the development of informational competences.

\section{Keywords}

Information. Social Inclusion. Information Professionals.

\section{INTRODUÇÃO}

Ainda que, em nosso país, as alterações sociais, econômicas e políticas da chamada "sociedade da informação" tenham se dado de forma muito específica, e pareça que a falsa impressão de homogeneização em outros países seja resultado de vieses metodológicos, não ficamos alheios aos impactos da globalização dos mercados, do avanço da ideologia 
neoliberal e da supervalorização da informação e do conhecimento nas últimas décadas. A esse respeito, Costa (2010, p. 180) afirma:

As consequências sociais das transformações organizacionais e tecnológicas da típica empresa capitalista foram diretamente sentidas no aumento do desemprego, com impactos decisivos na expansão e na criação de novas modalidades de trabaIho informal, na redução ou retirada das contrapartidas sociais dos empregos ofertados e na ampliação da heterogeneidade das condições de trabalho, de renda e de vida da população.

É sobre esse último aspecto que direcionaremos nosso olhar. Se os esforços para modernizar e industrializar o país durante o século XX não conseguiram resolver as desigualdades inter e intrarregionais, o heterogêneo processo de assimilação da chamada sociedade da informação os agravou. A população mais pobre, com menor escolaridade e qualificação profissional, permaneceu não só alheia ao mercado formal como apartada da distribuição das riquezas produzidas e distante do gozo pleno de direitos básicos, previstos no arcabouço legal e nos ideais que regem nossa República.

Esse grupo de indivíduos e famílias historicamente marginalizados, "a ralé brasileira", goza de uma "subcidadania" legitimada e naturalizada pelo discurso da meritocracia (SOUZA, 2018), da pobreza como acidente sociológico e superável por ajustes do sistema capitalista, quando na verdade é esse sistema que a produz, legitima e naturaliza. A existência de uma ampla parcela da população que trabalha de distintas formas apenas para sobreviver é fundamental para a manutenção de um restrito grupo que lucra desproporcionalmente e goza dos melhores prazeres do capitalismo.

O Estado, por sua vez, que deveria atuar mediando conflitos de interesse entre esses grupos, acaba se colocando à disposição dos rentistas, banqueiros, empreiteiros, empresários e toda sorte dos que circulam pelos mais elevados estratos da nossa sociedade. Aos que sobram dessa conta é dado apenas o que sobra.

O compromisso com a superação das diversas formas de exclusão social deve ser compartilhado por todos os indivíduos e instituições e, nesse contexto, parece claro que a ciência de modo geral, e mais especificamente cientistas e profissionais da informação não podem eximir-se de sua parcela de reponsabilidade. Para tanto, iniciaremos este estudo expondo as compreensões que adotamos sobre informação, inclusão e exclusão social por meio de uma revisão bibliográfica interdisciplinar, para então relacionar esses fenômenos e propor eixos de atuação vinculados à Ciência da Informação às profissões da informação (Arquivologia, Biblioteconomia, Gestão da Informação e Museologia) na promoção da inclusão social. Obviamente que não se busca aqui forçar um caráter utilitarista à pesquisa em Ciência da Informação ou em qualquer outra área, mas expor aspectos fundamentais relativos à relação entre a informação, o conhecimento e as tecnologias com o complexo e multidimensional fenômeno da exclusão social, que se materializa em profundos abismos entre indivíduos e grupos sociais.

\section{QUE COMPREENDEMOS POR INFORMAÇÃO?}

Os interesses em estabelecer um conceito unívoco de informação têm gerado inúmeras publicações e intensos debates entre os pesquisadores da Ciência da Informação. Saracevic e Wood (1986), Buckland (1991), Wersig (1993), Le Coadic (1996), McGarry (1999), González de Gómez (2000), Silva e Ribeiro (2002), Barreto (2002), Choo (2003), Rendón-Rojas (2005), Floridi (2005), Capurro e Hjorland (2007) e Frohmann (2008), são alguns dos 
exemplos de pesquisadores que abordaram a questão e cujas obras tiveram maior repercussão.

As distintas abordagens estão localizadas em espaços e tempos também distintos, e, além de estarem condicionadas por quadros epistemológicos e sociais diferentes, serviram também a variados propósitos, na medida em que cada pesquisador a elaborou com fins e interesses próprios, na ampla gama de campos de pesquisa da Ciência da Informação. Diante desse quadro, parece que reconhecer a multiplicidade de conceitos para qualificar um fenômeno tão complexo seria mais frutífero que buscar alguma heterogeneidade entre eles e, por esta razão, adota-se, nesta pesquisa, aquele que desponta como mais adequado sem, no entanto, ignorar a existência ou minimizar a importância daqueles que foram preteridos nesta escolha.

Adota-se, neste trabalho, a compreensão de que a informação é a expressão materializada do conhecimento, ou como enunciaria Gomes (2017, p. 31), após uma aprofundada análise dos conceitos já elaborados por outros autores, "compreende-se aqui a informação como conhecimento em estado de compartilhamento". Esta definição sozinha, no entanto, diz pouco sobre a compreensão de informação adotada. Ainda que satisfaça aos anseios acerca do que é o fenômeno informacional, precisa ser complementada pelo quadro contextual em que esse conceito se situa, ou melhor, o lugar a partir de onde esse conceito é visto e tratado neste estudo.

Diante disto, cabe esclarecer que a informação, ou mais precisamente, o conhecimento em estado de compartilhamento, não existe alheio às dinâmicas sociais em que está inserido. Uma vez que se configura como recurso fundamental para a condição humana no mundo (ARAÚJO, 2009), submete-se, e por vezes reforça, às relações de poder e desigualdade presentes em cada contexto social, tanto enquanto representação memorialística quanto como catalisador da criação de novos conhecimentos ou, como diria Barreto (2002, p. 49), como "[...] um instrumento modificador da consciência do indivíduo e de seu grupo social, pois sintoniza o homem com a memória de seu passado e com as perspectivas de seu futuro.". Cabe afirmar, portanto, que esse recurso não está disponível em condições de igualdade entre os distintos indivíduos e grupos sociais, e afeta a capacidade individual e coletiva de tomar decisões e de agir no mundo, implicando, inclusive, em relações desiguais de acesso a direitos, bens e serviços que afetam o desenvolvimento humano e cognitivo das pessoas, bem como seu bem-estar e qualidade de vida.

Indo mais além, e baseando-se na perspectiva da dialética marxista, Silva (2017, p. 206) propõe um conceito crítico-social da informação com duas características básicas a serem consideradas:

\footnotetext{
A primeira é que a informação não parte linearmente do sujeito/autor para o sujeito/usuário e nem é construída pelo sujeito/usuário a partir de modelos mentais, mas é a partir das relações sociais que a informação pode ser compreendida; a segunda é que a informação não é teoricamente gestada para ser aplicada, porém a partir das relações sociais, a informação é construída promovendo sentido teórico-prático (isso ocorre em face de que a informação possui um valor pragmático que auxilia na construção do conhecimento e este não pode ser gestado se não a partir das relações sociais).
}

Há um afastamento intencional, portanto, das abordagens físicas e cognitivas da informação, no sentido de compreendê-la não mais sob a perspectiva tecnicista da transmissão de mensagens, ou de seus aspectos estritamente subjetivos e de sua relação com o conhecimento do indivíduo, ainda que não se possa negar estas dimensões, mas, 
sobretudo, de ampliar o quadro de análise, percebendo a complexidade do fenômeno informacional e suas relações com o quadro social e histórico.

Em última instância, Martignetti (1999 apud CRUZ, 2013, p. 373-374) afirma que:

[...] na medida em que se considera a informação como um dos dois elementos fundamentais para o exercício do poder e, ainda, que o controle de informações adequadas e exatas confere vantagem a quem as detém, a restrição ou, num grau mais elevado, a exclusividade da informação passa a constituir um aspecto eminentemente político. Pois, da informação “...depende, de fato, a possibilidade de um controle difuso e apropriado do sistema [socioeconômico]" [...].

Cabe, portanto, o desafio de analisar contextos de dominação e desigualdade, em que a informação é utilizada para manter ou agravar os padrões estabelecidos, ou para contribuir com o rompimento dessas estruturas, contribuindo para a promoção da inclusão social por meio de estratégias que contemplem sua dimensão informacional, uma vez que a informação diz respeito intrinsecamente ao agir humano no mundo, enquanto seres protagonistas (PERROTTI, 2017), que interagem "[...] com as coisas do mundo, sempre mediados pela cultura." (BRITTO, 2016, p. 27).

\section{A DIMENSÃO INFORMACIONAL DA EXCLUSÃO SOCIAL}

A inclusão social pode ser brevemente definida como o conjunto de esforços que visam superar o complexo fenômeno da exclusão social. Desse modo, compreender este último conceito parece ser fundamental para que se possa discutir com maior profundidade a inclusão e sua dimensão informacional. Faleiros $(2006$, p. 4) define a exclusão social como "[...] negação da cidadania, da garantia e efetividade de direitos civis, políticos e sociais, ambientais e da equidade de gênero, raça, etnia e território.". Compreende-se daí que ainda que fortemente relacionada à pobreza, esses conceitos não se confundem, uma vez que a dimensão econômica constitui uma dentre as tantas dimensões desse fenômeno.

A exclusão social não se resume, portanto, à ausência de recursos materiais e suas implicações, mas é caracterizada, sobretudo, pelo posicionamento marginalizado de indivíduos e grupos na sociedade. Como reforça o mesmo autor ao afirmar que:

A exclusão é um processo dialético e histórico, decorrente da exploração e da dominação, com vantagens para uns e desvantagens para outros, estruturante da vida das pessoas e coletividades, diversificada, relacional, multidimensional, e com impactos de disparidade, desigualdade, distanciamento, inferiorização, perda de laços sociais, políticos e familiares, com desqualificação, sofrimento, inacessibilidade a serviços, insustentabilidade e insegurança quanto ao futuro, carência e carenciamentos quanto às necessidades, com invisibilidade social, configurando um distanciamento da vida digna, da identidade desejada e da justiça. (FALEIROS, 2006, p. 4).

Tal afirmação explicita o caráter complexo e multidimensional da exclusão social, situando-o na construção social de vulnerabilidades diversas que comprometem o pleno desenvolvimento individual e coletivo. Em sua revisão do corpus da literatura sobre inclusão e exclusão social, Vinson (2009) descobriu que todas as definições de exclusão apontam ao fato de os ambientes social e físico em que as pessoas vivem estarem implicados. Os riscos de exclusão para o indivíduo são identificados por Vinson (2009) como "[...] suporte limitado, incapacidade de acesso ao mercado de trabalho, alienação da sociedade e resultados 
educacionais mais pobres [...]" (VINSON, 2009, p. 7, tradução nossa), o que pode levar a um maior risco de privação de direitos. Warschauer (2004) sugere que a exclusão social prejudica não apenas aqueles que são excluídos, mas também a comunidade e a economia em geral.

Alvino-Borba e Mata-Lima (2011, p. 226) reforçam o caráter multidimensional do fenômeno e afirmam que "[...] é essencial uma análise holística de todos os problemas sociais para se definir eventuais medidas de combate à exclusão social.". Esse fenômeno, obviamente, está situado um contexto global cujas influências determinam as dinâmicas de exclusão/inclusão cujo eixo central se fundamenta na informação e no conhecimento.

A dimensão informacional da exclusão social caracteriza um cenário marcado pelas transformações tecnológicas que ocorreram a partir da segunda metade do século XX, incessantemente abordadas na literatura da área de Ciência da Informação, que ampliaram as possibilidades de conectividade e comunicação e alteraram as dinâmicas sociais, técnicas e econômicas em boa parte do globo, caracterizando a chamada interação globalizada e a competitividade dos mercados globalizados (FALEIROS, 2006), e consequente internacionalização da economia neoliberal (ALVINO-BORBA; MATA-LIMA, 2011). A despeito da utopia tecnológica que, de maneira bastante otimista, apontava para a solução de boa parte dos problemas humanos por meio do desenvolvimento de novas tecnologias da informação e da comunicação, a realidade tem apontado que os avanços tecnológicos trouxeram inúmeros benefícios mas acirraram problemas e assimetrias típicas do capitalismo, como o alargamento do hiato entre pobres e ricos (FALEIROS, 2006). Para Masuda (1980), por exemplo, na chamada sociedade da informação, o princípio da competição seria substituído pelo da sinergia, de modo que os indivíduos passariam a ter um objetivo social comum; tal afirmação, no entanto, não encontra correspondência numa sociedade em que se acirram a concorrência e a intolerância.

Para Ataíde (1997), "A Internet permite a disponibilização de dados e informações a qualquer momento e por qualquer pessoa ou instituição. Este fato ocasiona um mundo de informações colocadas de forma desorganizada e consequentemente de difícil recuperação.". Tal fato, por si só, já gera uma atividade econômica de custos consideráveis, a organização e o tratamento da informação, que pode limitar a ampla inserção da sociedade no processo de globalização. Some-se a isso o fato de que os próprios artefatos tecnológicos não estão disponíveis a todos, uma vez que muitas pessoas ainda veem suas necessidades básicas como água e comida comprometidas. Para Civille (1995 apud ATAÍDE 1997), indivíduos com laços fracos, carentes de acesso a uma rede mais ampla de relacionamentos como os fornecidos pela Internet, podem ser colocados em uma posição desvantajosa.

Caidi e Allard (2005) entendem que os excluídos enfrentam problemas substanciais de informação, em primeiro lugar relativos à busca de informações relacionadas às suas necessidades de informação, que podem dizer respeito a habitação, emprego, educação e saúde. Outros estudos, tais como os de George e Chaze (2009) e Bigelow (2010) também constataram que a informação é a necessidade mais crítica e observaram forte relação entre exclusão social e informação.

Perrotti e Pieruccini (2007, p. 52) analisam as contradições dessa realidade ao afirmar que:

As novas possibilidades de produção, circulação e recepção dos signos criaram um quadro cultural em que a falta convive lado a lado com o excesso, o fortuito com o permanente, o virtual com o real, embaralhando fronteiras e percepções que alteram irremissivelmente relações com o conhecimento e o saber. 
Ao que Santos, Duarte e Lima (2014, p. 39-40) complementam:

Examinando esse cenário, percebe-se a existência de uma dinâmica social dialética, que mesmo movida pela informação e não mais pela carência informacional, ainda pode ser identificados sujeitos que não possuem acesso, ou ainda não desenvolveram habilidades e competências para a busca e recuperação da informação.

A ideia de que o acesso limitado à informação restringe a capacidade de os indivíduos participarem plenamente da sociedade e tomarem decisões informadas tem sido vista, segundo Kennan et al. (2011), como impulsionadora do que foi denominado pobreza informacional. Chatman (1996) definiu um mundo de pobreza de informação como aquele em que uma pessoa não deseja ou não sabe resolver um problema crítico. Pessoas pobres em informação percebem-se desprovidas de quaisquer recursos de informação que poderiam ajudá-las.

Por exemplo, imigrantes, que frequentemente têm diferentes entendimentos da sociedade, porque o mundo que eles habitavam anteriormente pode ter sido muito diferente do novo mundo de seus países adotivos, podem experimentar pobreza informacional (CAIDI; ALLARD, 2005; MEHRA et al., 2008). Com o tempo, a pobreza de informação pode afetar a capacidade de ampliar as redes sociais, obter emprego, manter a saúde e conquistar acesso à educação formal, criando assim um ciclo de alienação, marginalização contínua e privação de direitos para esse setor da comunidade, como observam Lloyd, Lipu e Kennan (2010).

Um estudo realizado por Caidi e Allard (2005) que examinou a inclusão e a exclusão social de imigrantes no Canadá constatou que a falta de acesso à informação cria barreiras que impedem a participação plena dos imigrantes na educação, no trabalho e na vida cotidiana. Isso pode fazer com que aqueles que não têm acesso à informação sejam cada vez mais excluídos dos principais recursos de informação e, subsequentemente, não desenvolverem a capacidade de se estabelecerem totalmente, de aproveitarem oportunidades e de participarem ativamente da sociedade.

Assim, a exclusão social é vista como um problema de informação (KENNAN et al., 2011). Nesse contexto, as pesquisas sobre imigrantes no Canadá e Austrália indicam a necessidade de abordar opções para acesso à informação, provisão de informação e educação informacional de modos culturalmente apropriados, que reconheçam as diferenças culturais e proporcionem treinamento e acesso àqueles que não têm acesso ou compreensão sobre tecnologias da informação e comunicação.

De modo geral, pode-se afirmar, portanto, que a dimensão informacional da exclusão social está fundamentalmente relacionada ao fato de que, sem acesso às informações necessárias e sem condições de apropriar-se delas, em um quadro de pobreza informacional, os indivíduos veem reduzida sua capacidade de agir no mundo de modo protagonista, no sentido que Ihe atribui Perroti (2017), de primeiro lutador, cuja necessidade de ação no mundo comum, de todos, é existencial e relacional. Nesta mesma direção, Santos, Duarte e Lima (2014, p. 43) apontam que:

Os usuários informados e detentores de conhecimento poderão se posicionar criticamente frente às exclusões vividas e poderão desenvolver uma condição de autonomia, na medida em que serão agentes de transformação do espaço em que vivem, sentindo-se colaboradores ativos e integrantes do processo de desenvolvimento das atividades desse espaço. 
Tal contexto, resumido na Figura 1, possui impactos políticos, sociais e econômicos, dada multidimensionalidade da exclusão social. Do ponto de vista político, a pobreza informacional reduz a capacidade de participação dos indivíduos nas decisões coletivas, nas relações com o Estado, com o mercado, com a ciência e com movimentos sociais, desde o afastamento de espaços de deliberação e controle social à incapacidade de refletir criticamente para tomada de decisão em processos eleitorais. Socialmente, a pobreza informacional restringe o acesso a direitos fundamentais, como saúde, educação, água, e moradia adequada (MEDEIROS, 2015), motivo pelo qual Martins (2011) aponta o caráter instrumental da informação no campo da efetivação dos direitos, na mesma medida em que consiste em um direito em si.

Figura 1 - A dimensão informacional da exclusão social

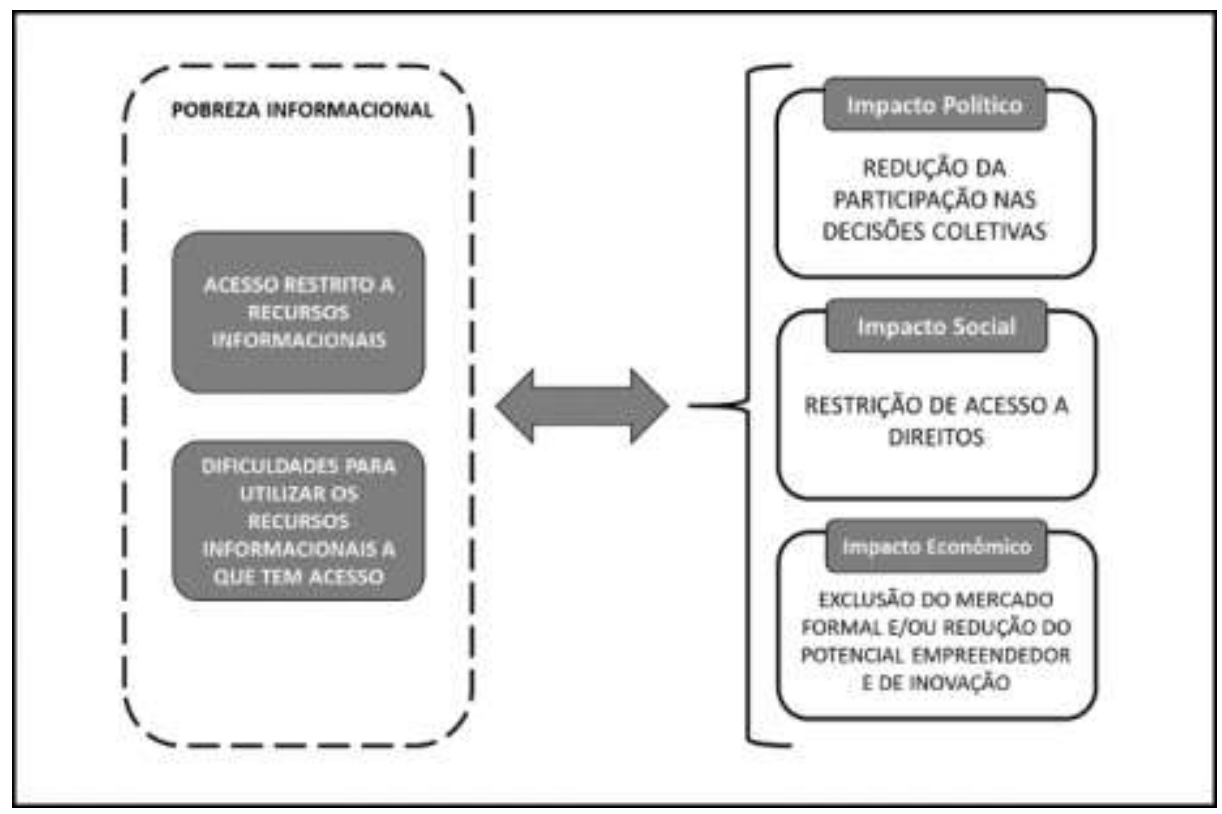

Fonte: Elaborado pelos autores (2019).

Do ponto de vista econômico, a crescente utilização de tecnologia nos processos produtivos reduz o número de postos de trabalho e aumenta a exigência por qualificação e formação dos profissionais. Quando relacionados, esses cenários geram um ciclo no qual quem não tem acesso à tecnologia e aos recursos informacionais não terá as competências exigidas pelo mercado e quem não atender a estas exigências não será capaz de produzir renda que lhe garanta acesso à tecnologia e aos recursos informacionais. Rodrigues et al. (1986), já na década de 1980, apontavam para o fato de que as habilidades informacionais dos indivíduos nas organizações já passavam a ser utilizadas como critério de hierarquização de funções e cargos, com os mais habilidosos no topo da pirâmide e os menos habilidosos em sua base ou fora dela.

Assim, excluídos dos mercados formais, muitos sujeitos excluídos socialmente e pobres informacionalmente lançam mão de atividades econômicas informais na tentativa de garantir seu sustento, ainda que isto não possa romper completamente com os ciclos de exclusão e pobreza. Em 2018, esse cenário de informalidade respondeu por $16,9 \%$ de todo o Produto Interno Bruto do Brasil (ETCO, 2018), consolidando uma tendência de crescimento iniciada no ano de 2016. Tsugumi (2006, p. 21 apud ALVINO-BORBA; MATA-LIMA, 2011, p. 226) "[...] considera o processo de exclusão social perverso, pois condiciona os excluídos a 
criarem situações que garantam a sua própria sobrevivência através do mercado de trabalho informal ou da ilegalidade.".

Mesmo ocorrendo majoritariamente ao largo da interferência estatal, estas atividades não estão alheias às influências do mercado globalizado e do acirramento da concorrência, em que a pobreza informacional constitui-se como fator de desvantagem para organizações e empreendedores, restringindo processos de inovação que se constituem como diferenciais competitivos para as organizações no mercado formal (PORTER, 1999) e, mais recentemente, para os próprios indivíduos no mercado informal.

Em síntese, Sen (2010) aponta a pobreza e a privação de capacidades, além da exclusão no processo de governança como fatores de exclusão social. Como fatores de inclusão, o mesmo autor traz a segurança, a proteção, a segurança social, os direitos democráticos e as oportunidades comuns de participação política.

Daí a compreensão da informação como recurso, apontada anteriormente, mas, sobretudo, como recurso potencialmente utilizável para superação das dinâmicas de exclusão, uma vez que se garanta condições de acesso e desenvolvam-se as habilidades e competências necessárias à sua apropriação. Caidi, Allard e Quirke (2010) enfatizam ainda a importância de os prestadores de serviços ou intermediários de informação trabalharem juntos para auxiliar a inclusão social das pessoas marginalizadas e excluídas. Corroborando com o que trazem Santos, Duarte e Lima (2014, p. 40):

[...] os sujeitos não se constituem como seres isolados, nem autônomos em relação à informação e ao pensar do coletivo, mas compõem conexões de informações, conhecimentos e saberes. Assim, a informação é um elemento indispensável para inserção do sujeito na sociedade, para isso instituições governamentais e nãogovernamentais, instituições sociais como escolas, universidades e unidades de informação, devem estar unidas para potencializar a inclusão dos sujeitos seja socialmente ou digitalmente.

Uma revisão da bibliografia e da literatura na área da Ciência da Informação indica que há um pequeno e lento desenvolvimento de pesquisa (ALLEN; MATTHEW; BOLAND, 2004; CAIDI; ALLARD, 2005; SRINIVASAN; PYATI, 2007) em relação à exclusão e inclusão, e o contributo que as bibliotecas e outras agências de informação podem fazer para o desenvolvimento e empoderamento dos cidadãos. Onde a pesquisa foi realizada, a literatura indica uma necessidade de abordar as opções de acesso à informação, provisão e educação em competência em informações de formas culturalmente apropriadas, que reconheça a diferença cultural na provisão de informações.

\section{TRAJETÓRIAS POSSÍVEIS PARA ATUAÇÃO DE CIENTISTAS E PROFISSIONAIS DA INFORMA- ÇÃO NA PROMOÇÃO DA INCLUSÃO SOCIAL}

Nesse cenário, cientistas e profissionais da informação devem assumir o desafio de elaborar estratégias para descontruir contextos de pobreza informacional, por meio da mediação e do desenvolvimento da autonomia informacional dos sujeitos, contribuindo para garantir-lhes o direito à informação, à leitura, à cultura e à memória. Para tanto, sugere-se, de modo suscinto, dois eixos de atuação para o enfrentamento da dimensão informacional da exclusão social, que podem ser aplicados em diversos contextos:

a) Garantia de acesso a recursos informacionais: por meio da oferta de serviços e ferramentas de informação, em diversos formatos e estruturas, de modo a atender às 
necessidades informacionais dos sujeitos, em bibliotecas, arquivos, museus, serviços de assistência social, saúde e educação, promovendo também sua inclusão digital. Os suportes de informações podem incluir uma variedade de canais, uma variedade de fontes dentro dos canais e uma variedade de mensagens contidas nessas fontes (JOHNSON, 2009). Esses canais e fontes de informação são definidos por Sonnenwald, Wildemuth e Harmon (2001) como recursos de informação, os quais são determinados social e individualmente pelas situações e contextos em que se encontra o indivíduo. Como bem afirmam Santos, Duarte e Lima (2014, p. 43-4), "[...] a informação por representar um bem social, que todos devem ter acesso, e se apresentar nos mais diversos suportes e tecnologias, amplia a responsabilidade dos profissionais da informação [...]". Tarapanoff, Suaiden e Oliveira (2002) chegam a afirmar que uma das características de nossa conjuntura socioeconômica é a banalização da tecnologia ao ponto de torná-la invisível. O acesso limitado a ela, no entanto, tem efeitos claros, e para os mesmos autores a "[...] provisão do acesso democrático a toda informação publicada [...]" (TARAPANOFF; SUAIDEN; OLIVEIRA, 2002 , p. 2) é uma das principais estratégias do novo desenvolvimento social.

\section{b) Desenvolvimento de Competências Informacionais: acessar recursos} informacionais, no entanto, não garante a superação do contexto de pobreza informacional. É preciso garantir que, uma vez que os recursos sejam acessados, os indivíduos sejam capazes de utilizá-los de modo a atender às suas necessidades de informação, o que Perrotti e Pieruccini (2007) chamam de apropriação da informação. Desse modo, há que se falar em desenvolver um conjunto de competências ligadas às atividades de acesso e de apropriação da informação; em tornar os indivíduos competentes desde uma perspectiva informacional. Ao analisar a informação, o usuário competente em informação leva em consideração como e por que a informação é fornecida, considera o discurso que envolve a produção e fornecimento da informação e o processo pelo qual a informação e o conhecimento são construídos e legitimados dentro de um ambiente particular (LLOYD, 2006). Portanto, segundo esse autor, as pessoas competentes em informações podem ser caracterizadas como aquelas que são enriquecidas, habilitadas e comprometidas com seus ambientes de informação. A competência informacional está alinhada à aprendizagem em contextos formais e informais (BRUCE; EDWARDS; LUPTON, 2007). Uma premissa central do conceito de competência informacional é o empoderamento das pessoas para tomar decisões e ações informadas por meio do uso crítico e reflexivo da informação, independentemente do formato. Sob o "guarda-chuva" da competência informacional, há uma série de competências pelo meio das quais o conceito foi definido e reconhecido inclusive por agências governamentais (AUSTRALIAN BUREAU OF STATISTICS, 2006): competência informacional em saúde, que inclui o conhecimento e as habilidades necessárias para entender e usar informações relacionadas a problemas de saúde; competência informacional em prosa, relacionada à capacidade de compreender e usar informações de vários tipos de textos narrativos, incluindo jornais, revistas e brochuras; competência informacional em documento, que mede os conhecimentos e as habilidades necessárias para localizar e usar informações contidas em vários formatos, incluindo tabelas e gráficos; e competência informacional digital, a capacidade de localizar, entender e avaliar informações de computadores. A competência informacional digital é cada vez mais 
importante, já que os governos e as agências fornecem informações e serviços por meio da Internet e mudam cada vez mais o foco da simples provisão de informações para uma expectativa de participação mais ativa dos usuários (CECEZ-KECMANOVIC et al., 2009).

Ambos os eixos sugeridos incidem diretamente sobre o contexto de pobreza informacional apontado na Figura 1. Todavia, buscar superá-lo exige a compreensão do modo como os indivíduos produzem, comunicam e usam a informação. As perspectivas de atuação aqui apontadas, devem ser operadas por profissionais e cientistas da informação, sobretudo, como um compromisso ético contínuo, corroborando com Schneider (2013), que afirma:

\footnotetext{
Teríamos então, no campo da ética, o compromisso, o cuidado e a competência dos pesquisadores e profissionais da $\mathrm{Cl}$ na avaliação crítica e na gestão da dinâmica global do processo informacional como um todo, tendo em vista a promoção de acessibilidade universal à informação (correta e adequada) para o bem viver, bem como a formação também universal de competências cognitivas.
}

Este trecho aponta diretamente para as possibilidades de atuação levantadas nesta seção, que consideram a informação como construto imbricado numa ordem econômica, social, cultural e política, marcada por estruturas de distribuição desigual de poder e da própria informação.

\section{CONSIDERAÇÕES FINAIS}

Ainda que haja um consenso implícito acerca da função social da Ciência e das profissões da informação, pouco tem se discutido, em termos teóricos, acerca da operacionalização do enfrentamento à exclusão social por parte desses cientistas e profissionais. Considerando a informação como conhecimento em estado de compartilhamento e como recurso distribuído em condições de desigualdade entre indivíduos e grupos sociais, deve-se reconhecer que seus processos de construção, comunicação e uso, uma vez que situados em um contexto social, econômico, político e cultural, não estão alheios às dinâmicas globais que acirram as desigualdades e colocam uma parcela significativa da população mundial às margens dos benefícios oriundos dos avanços no desenvolvimento de tecnologias da informação e da comunicação.

Deste modo, toda teoria e prática no campo da Ciência da Informação estão também intimamente relacionadas a esses processos, e silenciar diante deles implica em assumir uma posição em benefício daqueles que já são favorecidos pelas desiguais estruturas de poder implementadas em nesta sociedade. Uma vigilância ética contínua faz-se necessária, portanto, para que, mesmo no exercício das atividades e discussões mais técnicas do campo, a função social da Ciência da Informação, da Arquivologia, da Biblioteconomia, da Gestão da Informação e da Museologia seja cumprida e contribua para a construção de uma sociedade justa e igualitária. Se, no âmbito individual, a informação contribui para o gozo de direitos, para o exercício da cidadania, e para uma existência plena, autônoma e transformadora, no âmbito coletivo, é a informação que contribui para a implementação de sistemas democráticos, que valorizam a participação de cada cidadão e que têm como objetivo maior um estado de pleno bem-estar social. 
Os dois eixos de atuação aqui propostos - acesso a recursos de informação e desenvolvimento de competências informacionais - buscam reunir, didaticamente, um conjunto de ações e estratégias possíveis de serem implementadas, sob a ótica do fenômeno informacional e que podem contribuir para o enfrentamento à exclusão social. Esta discussão, no entanto, não se faz de forma exaustiva e outras ações, estratégias e eixos de atuação podem surgir, na medida em que a discussão ganhe corpo em na área da Ciência da Informação. Felizmente, muitos relatos de pesquisa e experiência têm demonstrado a efervescência de ações com fundamentos sociais, ainda que discussões teóricas a esse respeito sejam pouco difundidas.

A emergência de um paradigma social nesta área, como afirma Capurro (2003), não pode ser exclusivamente metodológica, mas deve incluir a construção de um corpus teórico robusto, uma visão finalística de transformação social e, sobretudo, um posicionamento epistemológico socialmente comprometido.

\section{REFERÊNCIAS}

ALLEN, M.; MATTHEW, S.; BOLAND, M. J. Working with immigrant and refugee populations: Issues and Hmong case study. Library Trends, Baltimore, v. 53, n. 2, p. 301-328, 2004.

ALVINO-BORBA, A.; MATA-LIMA, H. Exclusão e inclusão social nas sociedades modernas: um olhar sobre a situação em Portugal e na União Europeia. Serv. Soc. Soc., São Paulo, n. 106, p. 219-240, abr./jun. 2011. Disponível em: http://www.scielo.br/pdf/sssoc/n106/n106a03.pdf. Acesso em: 12 abr. 2019.

ARAÚJO, C. A. A. Um mapa dos estudos de usuários da informação no Brasil. Em Questão, Porto Alegre, v. 15, n. 1, p. 11-26, 2009. Disponível em:

https://seer.ufrgs.br/EmQuestao/article/view/9317/5802. Acesso em: 12 abr. 2019.

ATAÍDE, M. E. M. O lado perverso da globalização na sociedade da informação. Ciência da Informação, Brasília, v. 26, n. 3, set./dez. 1997. Disponível em:

http://revista.ibict.br/ciinf/article/view/767/796. Acesso em: 12 abr. 2019.

AUSTRALIAN BUREAU OF STATISTICS. Adult literacy and life skills survey, summary results. Australia, Cat no. 4228.0. Canberra, ACT: Australian Bureau of Statistics, 2006.

BARRETO, A. A. A transferência da informação para o conhecimento. In: AQUINO, M. A. O campo da Ciência da Informação: gênese, conexões e especificidades. João Pessoa: Ed. Universitaria, 2002. p. 49-57.

BIGELOW, M. Researching and educating Somali immigrant and refugee youth language learning: A journal of research in language studies, [S.I.], v. 60, p. 147-156, 2010.

BRITTO, L. P. L. No lugar da leitura: biblioteca e formação. Rio de Janeiro: MBL, 2016.

BRUCE, C.; EDWARDS, S.; LUPTON, M. Six frames for information literacy education: a conceptual framework for interpreting the relationships between theory and practice. In: 
BUCKLAND, M. K. Information as thing. Journal of the American Society for Information Science (JASIS), [S.I.], v. 45, n. 5, p. 351-360, 1991.

CAIDI, N.; ALLARD, D. Social inclusion of newcomers to Canada: no information problem? Library \& Information Science Research, [S.I.], v. 27, n. 3, p. 302-324, 2005.

CAIDI, N.; ALLARD, D.; QUIRKE, L. Information practices of immigrants. Annual Review of Information Science and Technology, [S.I.], v. 44, p. 493-531, 2010.

CAPURRO, R. Epistemologia e Ciência da Informação. In: ENCONTRO NACIONAL DE PESQUISA EM CIÊNCIA DA INFORMAÇÃO, 5, 2003, Belo Horizonte. Anais [...] Belo Horizonte: UFMG, 2003. Disponível em: http://www.capurro.de/enancib p.htm. Acesso em: 23 abr. 2019.

CAPURRO, R.; HJØRLAND, B. O conceito de informação. Perspectivas em Ciência da Informação, Belo Horizonte, v. 12, n. 1, 2007. Disponível em:

http://portaldeperiodicos.eci.ufmg.br/index.php/pci/article/view/54/47. Acesso em: 12 out. 2019.

CECEZ-KECMANOVIC, D.; et al. Youth online participation in government decision making challenges for e-democracy. Paper presented at the 20th Australasian Conference on Information Systems. Melbourne: Association of Information Systems, 2009.

CHATMAN, E. A. The impoverished life-world of outsiders. Journal of the American Society for Information Science, New York, v. 47, n. 3, p. 193-206, 1996.

CHOO, C. W. A organização do conhecimento: como as organizações usam a informação para criar significado, construir conhecimento e tomar decisões. São Paulo: Ed. Senac São Paulo, 2003.

COSTA, M. S. Trabalho informal: um problema estrutural básico no entendimento das desigualdades na sociedade brasileira. Cad. CRH [online], Salvador, v. 23, n. 58, p. 171-190, 2010. Disponível em:

http://www.scielo.br/scielo.php?script=sci arttext\&pid=S01039792010000100011\&lng=en\& nrm=iso. Acesso em: 12 out. 2019.

CRUZ, E. B. O direito à informação governamental: questões acerca da positividade e legitimação de um direito fundamental. Liinc em Revista, Rio de Janeiro, v. 9, p. 370-382, 2013. Disponível em: http://revista.ibict.br/liinc/article/view/3442/3005. Acesso em: 28 abr. 2019.

ETCO. Índice de Economia Subterrânea. 2018. Disponível em: https://www.etco.org.br/economia-subterranea/?sub=resumo. Acesso em: 28 abr. 2019.

FALEIROS, V. P. Inclusão Social e Cidadania. In: INTERNATIONAL CONFERENCE ON SOCIAL WELFARE, 32., Brasília. Anais[...], Brasília: 2006. Disponível em: https://www.icsw.org/images/docs/Events/2006 Brazil/17 07 PDF/vicente faleiros.pdf. Acesso em: 12 abr. 2019. 
FLORIDI, L. "Is Semantic Information Meaningful Data". Philosophy and Phenomenological Research, [S.I.], v. 70, n. 2, p. 351-370, 2005.

FROHMANN, B. O caráter social, material e público da informação. In: FUJITA, M.S.; MARTELETO, R.M.; LARA, M.G. (Orgs.). A dimensão epistemológica da Ciência da Informação e suas interfaces técnicas, políticas e institucionais nos processos de produção, acesso e disseminação da informação. São Paulo: Cultura Acadêmica; Marília: Fundepe, 2008.

GEORGE, U.; CHAZE, F. Tell me what I need to know: South Asian Women, social capital and settlement. International migration and integration, [S.I.], v. 10, p. 265-282, 2009.

GOMES H. F. Mediação da informação e protagonismo social: relações com vida ativa e ação comunicativa a luz de Hannah Arendt e Jürgen Habermas. In: GOMES H. F. et al. (Orgs). Informação e protagonismo social. Salvador: EDUFBA, 2017.

GONZÁLEZ DE GÓMEZ, M. N. Metodologia de pesquisa no campo da Ciência da Informação. DataGramaZero: Revista de Ciência da Informação, Rio de Janeiro, v. 1, n. 6, dez. 2000.

JOHNSON, J. D. An impressionistic mapping of information behavior with special attention to contexts, rationality, and ignorance. Information processing and management, [S.I.], v. 45, p. 593-604, 2009.

KENNAN, M.A.; et al. Settling in: the relationship between information and social inclusion. Australian Academic \& Research Libraries, [S.I.], v. 42, n. 3, p. 191-210, 2011.

LE COADIC, Y. F. A Ciência da Informação. Tradução: Maria Yêda F. S. de Filgueiras Gomes. Brasília: Briquet de Lemos, 1996.

LLOYD, A. Information literacy landscapes: an emerging picture. Journal of Documentation, [S.I.], v. 62, n. 5, p. 570-583, 2006.

LLOYD, A., LIPU, S.; KENNAN, M. A. On becoming citizens: examining social inclusion from an information perspective. Australian Academic and Research Libraries, [S.I.], v. 41, n. 1, p. 4253, 2010.

MARTINS, P. L. Acesso à Informação: um direito fundamental e instrumental. Acervo, Rio de Janeiro, v. 24, n. 1, p. 233-244, jan./jun. 2011.

MASUDA, Y. A sociedade da informação como sociedade pós-industrial. Rio de Janeiro: Rio/Embratel, 1980.

MCGARRY, K. O contexto dinâmico da informação. Brasília: Briquet de Lemos/Livros, 1999. 
MEDEIROS, F. G. G. O papel social da informação sob a perspectiva dos Direitos Humanos: por uma cultura de acesso e participação popular. 2015. 52 f. TCC (Graduação) - Curso de Gestão da Informação, Universidade Federal de Pernambuco, Recife, 2015.

MEHRA, B. et al. Aquí y allá (here and there) information-based learning corridors between Tennessee and Puerto Rico: The five Golden Rules in intercultural education. Education for Information, [S.I.] v. 26, n. 3, p. 151-168, 2008.

PERROTTI, E. Sobre informação e protagonismo cultural. In: GOMES, H. F.; NOVO, H. F. (Org.). Informação e Protagonismo Social. Salvador: EDUFBA, 2017. Cap. 1. p. 11-26.

PERROTTI, E.; PIERUCCINI, I. Infoeducação: saberes e fazeres da contemporaneidade. In: LARA, M. L. G.; FUJINO, A.; NORONHA, D. P. (Org.). Informação e contemporaneidade: perspectivas. Recife: Néctar, 2007. p. 47-96.

PORTER, M. Vantagem competitiva: criando e sustentando um desempenho. Rio de Janeiro: Campus, 1999.

RENDÓN-ROJAS, M. Á. Bases teóricas y filosóficas de la bibliotecología. México: CUIBUNAM, 2005.

RODRIGUES, S. B. et al. Tecnologia de informação nos serviços: o impacto na configuração do trabalho. Revista de Administração de Empresas, São Paulo, v. 26, n. 1, p. 43-56, mar. 1986. Disponível em: https://www.scielo.br/pdf/rae/v26n1/v26n1a04.pdf. Acesso em: 28 abr. 2019.

SARACEVIC, T.; WOOD, J. B. Consolidation l'information: guide pour l'évaluation, la reorganization et le reconditionnement de l'information scientifique et technique: version provisoire. Paris: Organisation des Nations Unies pour l'Education, la Science et la Culture, 1986.

SANTOS, R. R.; DUARTE, E. N.; LIMA, I. F. O papel do bibliotecário como mediador da informação no processo de inclusão social e digital. Revista Brasileira de Biblioteconomia e Documentação, São Paulo, v. 10, n. 1, p. 36-53, jan./jun. 2014. Disponível em: https://rbbd.febab.org.br/rbbd/article/view/279/289. Acesso em: 21 abr. 2019.

SCHNEIDER, M. Ética, Política e Epistemologia: Interfaces da Informação. In: ALBAGLI, S. (org.). Fronteiras da Ciência da Informação. 1. ed. Brasília: IBICT, 2013. 262 p.

SEN, A. Social exclusion: concept, application, and scrutiny. Social Development Papers. Office of Environment and Social Development Asian Development Bank, n. 1, 2000. Disponível em: https://www.adb.org/sites/default/files/publication/29778/social-exclusion.pdf. Acesso em: 18 abr. 2019.

SILVA, A. M.; RIBEIRO, F. Das "ciências" documentais à ciência da informação: ensaio epistemológico para um novo modelo curricular. Porto: Edições Afrontamento, 2002. 
SILVA, J. L. C. Fundamentos da informação I: perspectivas em Ciência da Informação. São Paulo: ABECIN Editora, 2017. 271 p. v. 1.

SONNENWALD, D. H.; WILDEMUTH, B. M.; HARMON, G. L. A research method to investigate information seeking using the concept of information horizons: an example from a study of lower socio-economic students' information seeking behavior. The New Review of Information Behavior Research, [S.I.], v. 2, p. 65-85, 2001.

SOUZA, J. Subcidadania Brasileira: para entender o país para além do jeitinho brasileiro. Rio de Janeiro: LeYa, 2018. 288p.

SRINIVASAN, R.; PYATI, A. Diasporic information environments: reframing. Journal of the American Society for Information Science and Technology, [S.I.], v. 58, n. 12, p. 1734-1744, 2007.

TARAPANOFF, K.; SUAIDEN, E.; OLIVEIRA C. L. Funções sociais e oportunidades para profissionais da informação. DataGramaZero: Revista de Ciência da Informação, Rio de Janeiro, v. 3, n. 5, 2002. Disponível em:

https://repositorio.unb.br/bitstream/10482/884/1/ARTIGO FuncoesSociaisOportunidadesPr ofissionais.pdf. Acesso em: 23 abr. 2019.

VINSON, T. Social Inclusion: the origins, meaning, definitions and economic implications of the concept of inclusion/exculsion. Canberra: Australian Department of Education, Employment and Workplace Relations (DEEWR), 2009.

WARSCHAUER, M. Technology and social inclusion: Rethinking the digital divide. Cambridge Massachusetts: MIT Press, 2004.

WERSIG, G. Information science: the study of postmodern knowledge usage. Information Processing \& Management, [S.I.], v. 29, n. 2, p. 229-239, 1993. 